\title{
A ativid@de de tutores na Educação a Distância: um olhar ergológico para o prescrito e o vivido nos ambientes virtuais de aprendizagem
}

\author{
The @tivid of tutors in distance education: \\ ergological a look to the prescribed and lived in virtual learning environments
}

Shirlei Marly Alves

Universidade Estadual do Piauí - Teresina - Piauí - Brasil

$\diamond$

\begin{abstract}
Resumo: Este artigo apresenta uma proposta de estudo sobre a atividade de tutoria on-line em cursos de Educação a Distância, com fundamentos na concepção ergológica de trabalho, na qual se ressalta a atividade discursiva como fonte de dados importantes sobre o modo como o trabalhador, como ser humano industrioso, investe de si em seu posto de trabalho. Por ser a linguagem o modo de concretização da atividade de tutoria, postulamos que o estudo científico a partir da episteme ergológica contribuirá para uma compreensão que vai além do que se prescreve para a tarefa do tutor, atingindo as nuances subjetivas da atividade, nas singularidades de cada cotidiano, em que o trabalhador, dialogando com professores e alunos, enfrenta os desafios de educar a distância.

Palavras-chave: Trabalho; Atividade de tutoria; Atividade de linguagem; Ergologia; Dialogismo

Abstract: This article proposes a study on the activity of online tutoring courses in Distance Education, with foundations in the design ergological work, in which he emphasizes the discursive activity as a source of important information on how the worker as human being industrious, invests himself in his job. Because the language mode of implementation of mentoring activity, we postulate that the scientific study from the episteme ergological contribute to an understanding that goes beyond what is prescribed for the task of the tutor, reaching the nuances of subjective activity, the singularities of each routine, the worker, talking with teachers and students facing the challenges of educating the distance.
\end{abstract}

Keywords: Work; Mentoring activities; Language activity; Ergology; Dialogism

\section{Introdução}

O trabalho, no contexto atual, apresenta-se como uma realidade bastante complexa, configurando uma arena de equilíbrios e desequilíbrios que atingem diretamente os trabalhadores, principalmente em função das mudanças nas relações trabalhistas, o desaparecimento de postos de trabalho e também a emergência de novos postos, com suas exigências, em termos de qualificação e condições de trabalho.

No que tange a aspectos desequilibradores, na visão de Antunes $(2008,2011)$, vive-se a erosão do trabalho regulamentado e contratado, que dominou o século XX. Em substituição, têm-se as formas de trabalho precarizado, como a empresa enxuta, caracterizada pelo mínimo de postos e o máximo de maquinário; o empreendedorismo, o cooperativismo ${ }^{1}$, o trabalho voluntário, os quais, segundo o autor, são formas de organização do trabalho que mascaram perdas para o trabalhador, em termos de direitos e garantias sociais historicamente conquistados.

Nesse contexto, consolida-se a visão de que o aumento da produtividade, com a conquista de novos mercados,

\footnotetext{
“As 'cooperativas' patronais tornam-se, então, contemporaneamente, verdadeiros empreendimentos, visando aumentar ainda mais a exploração da força de trabalho e a consequente precarização da classe trabalhadora. Similar é o caso do 'empreendedorismo' que cada vez mais se configura como forma oculta de trabalho assalariado e que permite o proliferar das distintas formas de flexibilização salarial, de horário, funcional ou organizativa" (ANTUNES, 2011, p.411).
} 
no cenário da globalização econômica, impulsionada pelos avanços tecnológicos, só se torna possível se as empresas reduzirem custos, principalmente com salários e obrigações sociais, sem sacrifício da qualidade de seus produtos. Isso também requer flexibilidade e capacidade de oferecer respostas rápidas e eficientes num mundo marcado pela mudança e pela incerteza, o que significa também superar os princípios fordistas de produção baseados na rígida divisão do trabalho, na prescrição individual das tarefas e na falta de autonomia dos operários na definição de métodos de trabalho.

Tal situação, portanto, parece demandar um novo perfil de trabalhador, "mais flexível", o que pode indicar, de um lado,a capacidade de adaptar-se às novas demandas e aos novos modelos de gestão e, de outro, a disposição de arcar com os custos de relações empregatícias sem as garantias trabalhistas socialmente conquistadas.

Quanto a esse segundo aspecto, Alves (1997) enfatiza o que denomina de "deterioração de postos de trabalho", relacionada ao aumento do número de empregos em subsetores de serviços cujas relações são, em grande parte, precárias, com as contratações acontecendo à margem das leis trabalhistas e salários menores, fato decorrente, também, do aumento do desemprego estrutural, o que leva trabalhadores, qualificados ou não, a buscar a sobrevivência, aceitando condições de "trabalho degradado" (ANTUNES, 2011).

Tal situação, em muitos aspectos, pode ser observada no âmbito do trabalho de tutoria tal como se desenvolve em programas públicos de EAD, a exemplo do Programa Universidade Aberta do Brasil (UAB), locus das pesquisas que vimos desenvolvendo acerca da atividade de tutoria on line.

Neste artigo, destacamos o caminho heurístico que já experimentamos, embasado na perspectiva ergológica, o qual nos possibilita desvendar a atividade tutorial a partir das vivências dos que a praticam, contribuindo para consolidar, no encontro entre os saberes dos trabalhadores e os conhecimentos acadêmicos, uma compreensão que vai além do prescrito, alcançando o eventício.

\section{O trabalho na Educação a Distância (EAD) - a tutoria}

A EAD é uma modalidade de ensino e aprendizagem que, no Brasil, vem se consolidando tanto no setor público quanto no privado, em cursos de formação acadêmica (graduação, pós-graduação, mestrado), bem como em cursos livres de aperfeiçoamento ou formação geral. Com esse modelo de educação, busca-se ampliar o acesso a quem não pode frequentar instituições presenciais, em função de tempo reduzido ou de obstáculos geográficos, bem como estender as oportunidades de estudo para além dos ambientes presenciais, já que o principal diferencial dessa forma de educação, atualmente, é o trabalho pedagógico realizado através de tecnologias digitais. Assim sendo, dispensam-se professores e alunos de estarem exatamente no mesmo local, ao mesmo tempo, como ocorre na educação presencial.

Nesse contexto educacional, o trabalho docente é dividido, sobretudo, pela organização das aulas em plataformas virtuais (DEPOVER et al., 2007), o que requer a participação de uma equipe multidisciplinar. Essa configuração também é devida ao grande número de alunos matriculados em um mesmo semestre, o que impõe a um só professor a responsabilidade de muitas turmas, o que torna necessária a presença de tutores, com a qual se busca garantir o êxito do estudante e a eficácia do sistema (PRETI, 2003).

$\mathrm{Na}$ Antiguidade Clássica, na Grécia, a tutoria dos jovens era assumida pelos filósofos, que se encarregavam de transmitir-lhes ensinamentos de Gramática, Retórica, Artes e Política. Em Roma, a tutoria se dividia conforme a idade das crianças, sendo exercida por escravos educados, que se incubiam de acompanhar e ensinar as crianças, e de supervisionar o trabalho dos professores, após aquelas atingirem mais de 7 anos de idade (SEMIÃO, 2009).

$\mathrm{Na}$ Idade Média, principalmente os clérigos eram tutores de jovens nobres, sendo que, embora encarregados de vários tutorandos, exerciam a tutoria individualmente. Com a institucionalização das universidades, o papel de tutoria se expande, sobretudo com a criação do New College, de Oxford, o qual, de acordo com Semião (2009), ficou conhecido como o berço do sistema tutorial, onde se adotava a sistemática de um estudante mais velho dar assistência aos mais jovens. Cabia a esses tutores a preocupação com o comportamento e o aproveitamento acadêmico dos tutoriados, agindo também como guardiães da conduta moral e da fé religiosa.

Mattar (2012, p. 24) comenta a primeira associação do termo tutoria com a tutela exercida na esfera jurídica e, por essa razão, considera infeliz a escolha desse termo para designar a ação que se desenvolve na EAD. Para defender seu ponto de vista, cita Bruno e Lemgruber (2009), autores que também defendem que essa nomenclatura deveria ser descartada ou reconceituada, pois, para eles, o tutor é um docente, e não apenas um animador ou monitor, e muito menos um repassador de pacotes instrucionais. Por mediar conteúdos e intervir na aprendizagem, o tutor, de fato, exerce a docência, sendo que, para isso, são-lhe exigidas competências de ordens diversas: subjetiva, tecnológica, didática e de conteúdo. Assim, concluem esses autores que é mais apropriada a denominação professor-tutor.

Consideramos importante essa discussão já que, no modelo atual de EAD,o termo tutor designa uma forma 
de docência integrada a uma concepção de ensino-aprendizagem cujo fundamento maior é a autonomia do aluno na construção de conhecimentos. Verifica-se, assim, que, longe de tutelar seres incapazes, ou de apenas supervisionar uma ação em curso, o tutor deve promover as condições para que os aprendizes se engajem cada vez mais na busca de conhecimentos e no processo de educar-se. Sousa et al. (2004), inclusive, alertam para o fato de que, equivocadamente, em muitas instituições que trabalham com cursos a distância, "O tutor passou a ser visto como um orientador da aprendizagem do aluno solitário e isolado que, frequentemente, necessita do docente ou de um orientador para indicar o que mais lhe convém em cada circunstância" (SOUZA et al., 2004, p. 6).

Nesse contexto, planejar, selecionar e preparar material didático, bem como tomar decisões quanto aos diferentes suportes pedagógicos (manuais, livros, vídeos e outros recursos disponíveis em ambientes virtuais), são funções desempenhadas pelos professores (muitas vezes ainda divididos em duas classes: os conteudistas e os formadores ${ }^{2}$ ). Já a orientação pedagógica mais direta - acompanhamento, atendimento constante e avaliação dos alunos - "passa a ser exercida não mais em contatos pessoais e coletivos de sala de aula ou atendimento individual, mas em atividades de tutoria a distância, em geral, individualizada, mediatizada através de diversos meios acessíveis" (BELLONI, 2009, p. 80).

Alonso (2010, p. 12) chama a atenção para outro aspecto importante dessa questão: a sobrecarga na atividade do tutor:

Muitas vezes, no discurso do "trabalho em equipe" tido, supostamente, como uma das bases da modalidade, é possível verificar que ao tutor fica destinada a maior parte das atividades de "ensino". Um dos problemas relacionados a isso é que o tutor não tem, profissionalmente, reconhecimento social/econômico/ empregatício compatível com suas atribuições, embora seja ele o responsável direto, na maioria dos sistemas constituídos na $\mathrm{EaD}$, pelo atendimento mais próximo aos alunos.

Nesse sentido, observa-se que, embora demandando providências relativas a sua situação trabalhista ${ }^{3}$, de acordo com o Censo da Associação Brasileira de Educação a Distância (ABED, 2012), tanto em cursos

\footnotetext{
2 Conforme definição no contexto do Programa UAB, já mencionada na Introdução desta tese. Alerta-se que outras denominações são feitas em outros contextos, como chamar de professor-autor aquele responsável pelo material didático impresso e coordenador da disciplina o professor que acompanha tutores e alunos em AVA.

3 No caso do programa UAB, segundo a Resolução CD/FNDE no 26 , de 5 de junho de 2009, o tutor é um bolsista, sendo que "V - (...) O valor da bolsa a ser concedida é de R $\$ 600,00$ (seiscentos reais) mensais, enquanto exercer a função" (BRASIL, 2009). Atualmente, como se pode verificar no Portal da CAPES, o valor é de R $\$ 765,00<\mathrm{http}: / / w w w . u a b . c a p e s . g o v . b r>$.
}

livres, como em cursos autorizados, a tutoria tornou-se uma das grandes preocupações das instituições, já que é o serviço que dá maior suporte ao aluno (pedagógico, de conteúdo, tecnológico e afetivo). Tem-se em conta, principalmente, que um dos critérios de qualidade dos cursos está justamente no tipo de acompanhamento e apoio ao discente, tendo em vista que são altos os riscos de evasão em cursos a distância. Esse contato mais próximo e frequente do tutor com os alunos sobreleva "a importância do seu papel no sucesso da aprendizagem e na manutenção destes alunos no processo. Em alguns casos, verifica-se que o papel do tutor é mais importante do que o material utilizado ou as plataformas de aprendizagem disponíveis (CARVALHO, 2007).

Essa grande importância do tutor na EAD faz com que, embora com modelos diversos, o sistema de tutoria seja o principal apoio do processo de aprendizagem on-line. Belloni (2009, p. 81) interpreta essa importância a partir de um ponto de vista organizacional, já que os tutores, situados em turmas diferentes, dinamizam o trabalho planejado pelo professor formador, o que leva essa autora a ver a tutoria como uma "transformação do professor de uma entidade individual em uma entidade coletiva”. Citando Blandim (1999), ela reforça essa visão ao destacar que o docente passa a gozar do "dom da ubiquidade e a participar, ao mesmo tempo, de várias ações ocorrendo em diferentes lugares" (BELLONI, 2009, p. 81).

Consideramos problemática essa concepção de Belloni (2009), em razão de que um ser "não repete outro", por conta de fatores como a história, a cultura, as experiências, os valores e os projetos de cada um. Portanto, embora estando prevista uma extensão do professor (planejador, arquiteto da disciplina ou do curso) na atividade de cada tutor, esses planos e arquiteturas ganham contornos específicos, em função das características individuais de cada tutor que os realiza, bem como das próprias dinâmicas pedagógicas ocorridas junto aos materiais didáticos e aos alunos. Longe de atuar como um autômato, recebendo comandos do professor e efetivando os planos destes, na interação com os alunos, o tutor estabelece os parâmetros adequados ao seu trabalho. Aliás, essa autonomia do tutor para configurar sua atividade, naquilo que lhe é possível, passa a ser um elemento fundamental para o êxito do empreendimento.

Nesse sentido, é consensual em estudos sobre o tema, e muitas práticas referendam esta posição, que o tutor é o sujeito responsável pelo acompanhamento do aluno em ambiente virtual de aprendizagem, o que implica propiciar uma assistência que visa garantir o melhor desempenho dos aprendentes em relação às tarefas em que se engajam. Desse modo, para concretizar essa complexa tarefa, seu trabalho deverá ser pautado pela reflexão e replanejamento 
constantes, e não por uma repetição mecanizada de atos preestabelecidos por outrem.

Pelo exposto, observa-se que, na literatura, a docência em EAD é descrita como uma atividade diferenciada em função das demandas específicas da modalidade educacional, bem como da concepção de ensino e aprendizagem em que se apoia, cuja tônica é a construção dos conhecimentos, e não a transmissão. Nesse contexto, ganha relevo a mediação pedagógica, a qual se diferencia do modelo tradicional de escola por se pautar em uma ação docente de orientação, de incentivo, de motivação e de monitoramento, com vistas a levar os alunos a se tornarem mais senhores de seus percursos e menos dependentes de uma autoridade de saber.

Ressalta-se que, paralelamente a afirmações categóricas sobre a atividade dos tutores, há também questionamentos que evidenciam uma busca de estabelecimento de uma identidade para esse profissional, notadamente pela polidocência, que caracteriza a EAD (MILL, 2006), e ainda pela herança que o termo carrega. Sobre isso, Silveira $(2005$, p. 06) questiona a identidade do tutor:

\begin{abstract}
Quem seria então o Tutor? Um mestre? Um educador? Aquele que ultrapassaria a visão restrita do especialista? Um educador que transcende o papel de motivador, de facilitador? Um educador que sustenta uma reflexão sobre a complexidade da ação educativa, mesmo a distância, ultrapassando os modelos lineares? Um tutor que, para organizar situações que promovam a aprendizagem dos alunos, transgride algumas normas já padronizadas e tão confiáveis?
\end{abstract}

Acreditamos que esses questionamentos, bem como a divisão de trabalho que, no âmbito do Programa Universidade Aberta do Brasil, coloca em instâncias diferentes professores e tutores, repercutem no modo como esses sujeitos (com destaque para os tutores) concebem seus trabalhos e mobilizam competências para realizá-lo.

Nesse sentido, Alves (2011a), em pesquisa que desenvolveu junto a tutores de uma universidade pública, constatou uma zona conflituosa na dinâmica das atividades docentes, principalmente em razão da falta de clareza com relação às tarefas dos professores, o que, segundo os tutores investigados, levava a que eles próprios, de acordo com suas perspectivas, recobrissem lacunas pedagógicas deixadas pelos professores. Outro achado dessa pesquisa diz respeito ao modo como os tutores concebem a si mesmos em seu trabalho, destacando-se várias dimensões de atuação, como se verifica na fala seguinte (em transcrição literal do texto enviado por um tutor pesquisado), em que destaca uma ação de preencher um vazio sentido pelos alunos.
Acompanhamos aos alunos com suas dúvidas, passamos orientações, e também os motivamos, pois o ensino a distancia, os alunos muitas vezes se sentem sozinhos. E lá estamos nós tutores, para estreitar esse "vazio" que acreditam eles, pela ausência do professor. (T04) (ALVES, 2011b, p. 36)

Como o tutor destaca, trata-se da sensação de um vazio, ou de solidão, que pode acometer o aluno de cursos a distância, em virtude da "ausência" do professor e dos colegas, em contraposição à presença física em uma sala de aula presencial. Nesse sentido, o tutor é impelido a "estreitar esse vazio", a fim de evitar a desmotivação no aluno. Para isso, evidentemente, precisa estar atento para diagnosticar situações que requerem um empenho maior nesse sentido, sem que possa visualizar o corpo, o gesto ou o olhar do aluno. Tendo como recursos apenasas mensagens ou os silêncios no ambiente virtual, o tutor deverá orientar sua atuação para manter o aluno motivado e evitar a evasão.

Por essas e outras razões, pode-se afirmar que é no transcurso de suas atividades, nos seus possíveis e impossíveis nos AVA, que o tutor refina sua atenção para situações problemáticas, como, por exemplo, a do aluno diante do "vazio" na educação a distância. Ou seja, nenhuma norma regulamentadora de sua ação determinará a aptidão do tutor diante das mais diversas (e muitas vezes inesperadas) situações com que se depara, nem muito menos lhe dirá o que deve fazer em cada situação específica. Isso se efetiva a partir do modo como lida com sua atividade, dos aprendizados que constrói cotidianamente, isto é, dos usos de si requeridos pelas demandas específicas que enfrenta.

Esse quadro ilustra um aspecto importante acerca das atividades de trabalho, nas quais o trabalhador, como um ser humano industrioso (SCHWARTZ, 2002), não funciona como um autômato aplicador de regras precedentes, ou repetidor de comportamentos estandartizados, mas, no quadro de suas demandas cotidianas, age de forma estratégica e criativa, renormalizando suas atividades, mobilizando e construindo competências, de acordo com suas concepções e valores. Essa perspectiva do trabalho caracteriza o campo da Ergologia.

\section{Um olhar ergológico para a tutoria em EAD}

No Brasil, a docência tem sido objeto de muitas investigações, predominando o interesse para aspectos em que essa atividade não é considerada, necessariamente, como um trabalho, mas, principalmente, como uma prática educativa. Nesse sentido, têm-se trabalhos que se voltam para o "efeito professor", com o objetivo de verificar como a ação docente repercute no aprendizado 
dos alunos (TARDIFF; LESSARD, 2011); outros buscam analisar características específicas das práticas pedagógicas ou, ainda,diversos aspectos da formação do professor (LOUSADA; BARELLI, 2011). Outro ângulo, não menos importante, é o da pesquisa com foco na questão trabalhista, em estudos sobre profissionalidade e profissionalização docente, na qual a atenção é dada à docência como uma profissão, em seus aspectos históricos, regulamentações, status, organização políticosindical, conquistas trabalhistas e outros fatores atinentes a esse universo (TARDIFF; LESSARD, 2011). Lousada e Barricelli (2011, p. 225) salientam que, nessas pesquisas, o ensino não é visto como um trabalho, nem consideram "as reconfigurações do agir educacional construídas nos mais diversos textos: da instituição escolar, de prescrições, elaborados por professores (auto-prescrições), alunos e outros envolvidos na situação [...]".

Como trabalho, a docência também pode ser estudada a partir da perspectiva de quem a desenvolve, com foco no que fazem os docentes, no dia-a-dia de suas atividades, opção adotada nesta pesquisa, em que o empreendimento investigativo vai ao encontro do métier da atividade, tendo em conta as condições subjetivas e intersubjetivas que lhe dão concretude em determinados contextos sócio-históricos. O intento é, pois, identificar o que, de fato, acontece na singularidade que caracteriza a atividade humana industriosa ${ }^{4}$, tendo-se como via de acesso aspráticas linguageiras ligadas às situações de trabalho, em consonância com a episteme ergológica.

Durrive e Schwartz (2008) explicam que a concepção fundamental da Ergologia é a do reconhecimento da atividade humana como um debate de normas, no sentido de "abarcar a complexidade da constante renormalização das normas antecedentes (o trabalho prescrito, para a Ergonomia) e do patrimônio histórico acumulado sobre a própria atividade" (PORTO, 2011, p.276). Nesse sentido, apresenta uma abordagem científica voltada ao estudo do trabalho humano em situação (atividade), "procurando compreender o seu processo e dar respostas práticas às situações e aos impasses implicados na relação estabelecida entre o patrimônio cultural acumulado sobre o trabalho (ensinado) e o patrimônio vivo das atividades do trabalho" (SAMPAIO, 2003, p. 150).

O trabalho aqui é um momento de vida, composto de uma sucessão de eventos, sendo a atividade "conduzida a partir de uma história local, segundo as apostas e as urgências de diferentes protagonistas" (DURRIVE, 2011, p. 48). É, pois, nessa confluência do instituído e do reinventado, ou recriado, que se deve considerar o trabalho real. No trabalho, o agente efetiva a sua atividade não apenas executando automaticamente funções predefinidas, mas envolvendo-se num complexo processo de gestão, que envolve avaliações e tomadas de decisões relativas ao modo de estar no ambiente de trabalho e de mantê-lo estável. Desse modo, "Para apreender as diversas competências implicadas nessa relação dicotômica - trabalho prescrito e trabalho real - faz-se necessário lançar um olhar sobre o sujeito desse trabalho, para compreender a forma como ele pensa, planeja, executa e administra suas tarefas" (SAMPAIO, 2003, p. 150).

Essa proposta de análise da atividade de trabalho, que intenta apreendê-la em suas múltiplas dimensões é altamente adequada à investigação sobre a tutoria em EAD, trabalho inserido no mundo contemporâneo das relações de serviço e cujo objeto de trabalho não se dirige a uma coisa inerte, já que efetivamente o docente (professor, tutor) dirige sua atividade a um semelhante, o qual busca transformar, no processo educativo, tendo a linguagem como instrumento. Desse modo, atividade de trabalho e atividade de linguagem se amalgamam, tornandose a segunda uma via privilegiada de compreensão da primeira.

\section{Análise dialógica do trabalho}

O acesso ao mundo do trabalho pela via da linguagem, concebida como atividade estruturante das demais atividades humanas compreendidas a partir de seus determinantes em contextos sócio-históricos é o ponto basilar da Ergolinguística, ou linguística do trabalho, a qual, como esclarece Porto (2011, p.275), "compreende o trabalho e a linguagem como atividades situadas, e a relação entre essas atividades é abordada através de métodos de coleta e análise de dados, entre os quais se destacam o método dialógico-discursivo, uma forma de conhecimento de sujeitos sociais via discurso".

Desse modo, a concepção de linguagem a conduzir o trabalho do analista do trabalho só poderá ser aquela cuja primazia esteja na relação entre sujeitos, na dinâmica ininterrupta dos discursos situados, os quais engendram formas de vida, na arena dialógica em que os seres humanos se encontram. Nesse sentido, é na teoria dialógica do Círculo de Mikhail Bakhtin que se fundamentam as análises das práticas linguageiras no trabalho, opção metodológica adotada nesta pesquisa.

Nesse autor também se encontra a concepção de ato (postupok), como definido nos primeiros escritos de Bakthin ${ }^{5}$.

\footnotetext{
4 Atividade industriosa diz respeito ao ato de trabalho, no sentido de mestria, de habilidade. (DURRIVE, SCHWARTZ, 2008).

5 "K filosofiipostupka" é o título dado por Sergei Bocahrov ao texto de Bakthin, datado do início dos anos vinte do século passado, conforme esclarece Augusto Ponzio, no prefácio da edição em português, com tradução de Miotello e Faraco (da qual nos valemos), lançada em 2010 intitulada Para uma filosofia do ato responsável. Há traduções em diversas línguas: francês, italiano, inglês, espanhol e alemão.
} 
Postupok é um ato de pensamento, de sentimento, de desejo, de fala, de ação, que é intencional e que caracteriza a singularidade, a peculiaridade, o monograma de cada um, em sua unicidade, em sua impossibilidade de ser substituído, em seu dever responder, responsavelmente, a partir do lugar que ocupa, sem álibi e sem exceção.(PONZIO, 2010, p. 10)

Encontra-se, nessa visão, o ato como uma resposta ativa e responsável dos sujeitos (responsiva) diante do mundo, ou seja, como manifestação de sua consciência no existir concreto, uma forte correlação com a definição de trabalho como atividade situada, efetivada pelos componentes da subjetividade do trabalhador (suas singularidades), tal como a definem a Ergologia e as ciências com que dialoga. Bakhtin (2010) concebe o existir em sua eventicidade, ou contingência, como um ato histórico, portanto em devir, assim como o trabalho, ergologicamente concebido como momento de vida, sucessão de eventos, conduzido a partir de uma história local dos seus protagonistas (DURRIVE, 2011).

O filósofo russo, a partir dessa perspectiva de ato enquanto evento único, singular, vivível por um ser em sua concretude, elaborou uma longa explanação filosófica acerca da impossibilidade de se ter, na abstração teórica, um conhecimento completo do ser e de sua existência. O mundo como conteúdo do pensamento científico é, para Bakhtin (2010, p. 30), "um mundo particular: é um mundo autônomo, mas não um mundo separado; é antes um mundo que se incorpora no Evento único e unitário do ser através da mediação de uma consciência responsável, em uma ação real". Evidencia-se uma das bases epistemológicas do pensamento de Bakhtin, contrário à excessiva racionalização do mundo, em detrimento das considerações de elementos da ordem do social, do histórico, do subjetivo - e seus componentes de incerteza e de inacabamento.

Trata-se de uma atitude recorrente em Bakhtin (2010), uma crítica contundente ao racionalismo, que tende a universalizar o que apreende, sem levar em conta o singular, privilegiando a lei geral, e não o evento; o sistema em oposição ao ato individual. "Incomoda-lhe um sistema em que não há espaço para o individual, o singular, o irrepetível, o eventício" (FARACO, 2009, p. 20). A crítica de Bakhtin (2010) ao teoricismo incide principalmente na pretensão universalista da ciência, a qual parte do pressuposto de que um enunciado universal se deduz necessariamente da ação individual ou, ainda, de que asserções universais consigam dar conta de uma explicação para cada ato humano.

Para Bakhtin (2010), o mundo da vida, dos acontecimentos não se pode apreender a partir de uma cognição teórica, mas sim de uma "razão que se orienta para o evento único do ser e pela unicidade de seus atos efetivamente realizados; ou, em outras palavras, que se orienta a partir do vivido, i.e., do interior do mundo da vida" (FARACO, 2009, p. 19). Isso não significa que o discurso científico não tenha sua validade, "todavia não é conhecimento último, mas apenas um momento técnico auxiliar dele" (BAKHTIN, 2010, p. 107).

É perceptível, reiteramos, a convergência entre essa concepção de ato, em Bakhtin (2010), e a de atividade, conforme a episteme ergológica, visto que, em ambas, o agir humano ocorre em eventos únicos, com as singularidades que lhe são inerentes; logo, só podem ser apreendidos no contato do pesquisador com os sujeitos em seu existirevento. Assim é o caso dos trabalhadores, considerados não como objetos de observação, mas, sobremaneira, como seres singulares, que, no seu cotidiano de trabalho, mobilizam competências construídas e reconstruídas a partir de sua história, emoções, memórias e outros elementos de natureza subjetiva.

Nesse sentido, Schwartz (2002) enfatiza a necessidade de serem os locais de trabalho os espaços privilegiados onde os estudiosos, ouvindo e interagindo com os trabalhadores, poderão ter acesso a suas experiências, em sua multidimensionalidade - incluindo não apenas o que fazem, ou que dizem, mas também o que não fazem, o que não dizem, o que intencionam sem realizar, o que acabam realizando sem planejar (CLOT, 2011).

Sobre concepções bakhtinianas como base para uma metodologia de pesquisa, é sempre importante considerar que, embora não apresentando um método de pesquisa (BRAIT,1996; FARACO, 2009), o conjunto das obras do Círculo de Bakhtin deu origem a uma análise/ teoria dialógica do discurso que propicia uma heurística apropriada a um percurso investigativo, cujos elementos basilares são os enunciados proferidos pelos homens nos inúmeros eventos da vida. Nesse sentido, tem-se, nas postulações bakhtinianas, "grandes diretrizes para construirmos um entendimento mais amplo das realidades em estudo" (FARACO, 2009, p. 40).

Outra das grandes diretrizes, intimamente ligada àquela que considera válido o conhecimento do homem em suas singularidades, está a de linguagem e de humanização ligadas ao social. Nesse sentido é na linguagem e pela linguagem que se constrói a consciência humana, isto é, vem de fora, do outro (do não eu), do social, a base com que o ser humano configura sua compreensão e consequentes relações com o mundo. E isso se dá pela via da linguagem, que consubstancia o linguístico e o ideológico que lhe são inerentes.

O meio social é o lugar da grande corrente discursiva na qual emergimos como seres humanos, portanto como seres de discurso, no incomensurável diálogo que atravessa os tempos. Essa concepção dialógica, que enfatiza a natureza inter-humana da linguagem, constitutiva 
das subjetividades, se mostra a mais adequada para os estudos ergológicos, já queo enfoque na complexidade do ser humano e do seu trabalho impõe que se considere a língua como uma atividade concreta de trocas verbais, e não apenas aquelas que ocorrem no face-a-face de uma conversa entre duas pessoas, como também as que se verificam no longo e ininterrupto diálogo entre os dizeres que compõem o grande fio discursivo tecido por todos os enunciados realizados e a realizar (FRANÇA, 2002).

O enunciado é, assim, o lugar privilegiado do dialogismo, processo que não se restringe à relação direta, face a face entre dois interlocutores, embora esteja aí a gênese do dialogismo, mas, sobretudo, se estende ao um grande e ininterrupto diálogo entre discursos. Isso significa que, ao nos reportarmos aum determinado objeto do mundo, não o encontramos "em essência", neutro, mas já transformado em objeto de discurso(s). Nesse encontro, estabelecemos relações dialógicas (de concordância, de polêmica, de confronto etc.), as quais incidem não apenas sobre o objeto, mas também sobre esses outros discursos. Desse modo, um objeto é sempre um objeto já discursivizado; portanto o que se diz sobre ele é o que ele representa (no interior dos diversos discursos) num determinado contexto social e histórico. Nesse sentido, já está ideologicamente marcado e, assim, ao enunciar, o sujeito necessariamente se insere nesse élan discursivo sobre o objeto, polemizando ou concordando com esses outros dizeres.

O conceito de relações dialógicas como base dos procedimentos metodológicos para compreender o trabalho de tutoria se mostra altamente proveitoso por ser esta uma atividade discursiva, em que a palavra está no "coração da atividade", como diz Lacoste (1998). Orientar-se pelo dialogismo, na compreensão desse objeto de pesquisa, obriga o pesquisador adirigir o seu olhar, na atividade que investiga, para as relações entre sujeitos e, necessariamente, entre discursos.

Nos estudos sobre o trabalho, isso significa ter em conta a presença de diferentes vozes discursivas na tessitura do que é dito sobre o trabalho e, também, nas práticas de linguagem que configuram o próprio trabalho. Nesse sentido, na pesquisa sobre tutoria em EAD, a atenção se volta para as interlocuções entre o tutor e demais sujeitos envolvidos no trabalho de tutoria, reveladoras das relações constitutivas dessa atividade de trabalho. Nessa arena discursiva, de encontro com os outros, é essencial a consideração do modo como se efetivam as relações de alteridade no seio dos discursos sociais entretecidos na contingência humana.

Essa inevitável e necessária presença do outro (o que está fora de mim) na constituição do eu se traduz nos discursos que, no domínio social, engendram a constituição do indivíduo. O dialogismo funda, pois, a alteridade como constituinte do ser humano e de seus discursos, já que é a palavra do outro que nos traz o mundo exterior e, em resposta a ela, é que passamos a nos inserir nesse mundo. Entretanto, a pluralidade dos homens encontra seu sentido não numa multiplicação quantitativa dos "eu", mas naquilo em que cada um é o complemento necessário do outro (BAKHTIN, 1997, p. 12).

Nessa postulação de Bakhtin (1988), pode ser apoiada a análise das elocuções de tutores participantes de pesquisa, devendo o pesquisador procurar, nas relações com o outro a quem o trabalhador se dirige (o próprio pesquisador, professor, alunos, coordenadores e outros), os indícios do ser que, nos eventos de sua atividade de trabalho, se define, renormalizando sua prática. Nesse sentido, ainda de acordo com a visão bakhtiniana, é em uma atitude ativamente responsiva em relação ao outro que nos construímos e passamos a atuar no mundo, através dos signos com que enunciamos. Não sendo estes neutros, mas carregados de ideologia, os enunciados, longe de serem apenas formas de comunicação, são, sobretudo, lugar de embates, de mútuas influências, de jogo de poder, de construções identitárias.

A reação à palavra alheia é, assim, sempre ativa e se traduz em uma resposta - a compreensão. Esta é também palavra (de adesão, de conflito) ou a contrapalavra do respondente. Sempre que enuncia, o locutor já postula esta compreensão responsiva, seja em forma de adesão, objeção, execução etc. Compreender a palavra, nesse sentido, é orientar-se em relação a ela, encontrar seu lugar adequado no contexto correspondente: “[...] A compreensão é uma forma de diálogo [...] Compreender é opor à palavra do locutor uma contrapalavra" (BAKHTIN [VOLOCHINOV], 1988, p. 131).

Em eventos de pesquisa, nos enunciados de tutores, a busca é por perceber a atividade de trabalho na compreensão responsiva desses trabalhadores, manifesta a outros enunciados, na dinâmica de sua atividade. Por exemplo, em sua contrapalavra ao discurso prescritivo, isto é, no seu modo único e singular de responder às determinações institucionais, junto ao aluno e ao professor formador, procuramos encontrar o fundamento ideológico que leva a atuar como atua: seus valores, suas crenças, suas experiências e aspirações.

No uso da palavra, Bakhtin (1997) destaca ainda o acento apreciativo que o locutor revela no tom emocionalvolitivo com que constrói a sua contrapalavra, a qual se faz na apropriação e inerente reelaboração que faz da palavra alheia. Isso porque não repetimos a palavra do outro, mas a incorporamos como palavra nossa, à medida que lhe imprimimos ressignificações e as acentuamos axiologicamente. Esse acento avaliativo se mostra no tom do enunciado. A entonação é, assim, um lugar de fronteira, onde a vida (e seus valores) se encontra com a língua e 
a transforma em enunciado, manifestação de um lugar único e singular do ser que toma a palavra para dizer. A entonação é, pois, o lugar do encontro entre o linguístico e o social, do dito com o não-dito. Situando-se sempre na fronteira entre o dito e o não-dito (mas presumível), a compreensão da palavra entonada requer necessariamente o conhecimento dos julgamentos de valor (axiologia) de um grupo social. Nesse sentido, é preciso considerar onde se situam locutor e interlocutor e qual o seu horizonte social comum. A dimensão axiológica (o tom emotivo-volitivo, como é denominado em Para uma filosofia do ato) é, portanto, parte inalienável do signo, da palavra viva.

Nessa perspectiva, a interpretação dos enunciados na pesquisa toma a entonação como índice importante a revelar a relação do sujeito trabalhador com a atividade que desenvolve e as arbitragens que promove. Ao enunciar, como diz Bakhtin (1997), o locutor seleciona e organiza os elementos linguísticos, fundamentado no valor social atribuído ao objeto, o qual não tem valor em si mesmo (como essência), tampouco se trata de uma valoração individual, mas situada num horizonte social em que o sujeito se situa e no qual encontra o seu lugar.

Desse modo, o pesquisador do universo do trabalho, ao se apoiar nas concepções desenvolvidas por Bakhtin e o Círculo, não se atém a uma análise do linguístico strictu sensu, pois "o enfrentamento bakhtiniano da linguagem leva em conta as particularidades discursivas que apontam para contextos mais amplos, para um extralinguístico incluído na situação e que, necessariamente, a constitui" (BRAIT, 2006, p. 26).

Desse modo, ao estudar a atividade do trabalhador tutor, busca-se verificar seus posicionamentos, ou seja, a sua resposta (réplica) às vozes que descrevem e prescrevem a sua atividade, bem como a outras vozes com que interage no seu dia a dia, provindas do professor e do aluno, com os quais realiza seu trabalho. É nessa cadeia de atividades que se define o conjunto, ou seja, no âmbito das relações que mantêm entre si é que ocorrem as tomadas de posição, constitutivas da linguagem, as quais já envolvem uma resposta ativa (BAKHTIN, 1997).

\section{Conclusão}

Em nossas experiências com a pesquisa qualitativa acerca da atividade de tutoria em EAD, verificamos a força heurística da perspectiva ergológica para uma compreensão sedimentada na comunhão, ou dialogia, entre os saberes acadêmicos e aqueles advindos do ser humano industrioso, vívido em sua atividade.

Desse modo, defendemos que o saber sobre a tutoria em EAD, uma atividade ainda em processo de consolidação em termos de uma identidade própria, em muito poderá se beneficiar de um adentramento pela via dos discursos dos que, cotidianamente, a concretizam, nos meandros de uma docência complexa, que desafia o tutor a um diálogo especial com seus parceiros (professores, alunos, coordenadores, técnicos), no modelo da EAD efetivada em ambientes virtuais.

\section{Referências}

ABED - ASSOCIAÇÃO BRASILEIRA DE EDUCAÇÃO A DISTÂNCIA. Censo ead.br: relatório analítico da aprendizagem a distância no Brasil 2011. São Paulo: Pearson Education do Brasil, 2012. Disponível em $<$ http://www.abed.org.br/censoead/ censo2012.pdf>. Acesso em: 14 nov. 2012.

ALONSO, Kátia Morosov. A expansão do ensino superior no Brasil e a EaD: dinâmicas e lugares. Educ. Soc., Campinas, v.31, n.113, p.1319-1335, out.-dez. 2010. Disponível em $<$ http://www.cedes.unicamp.br> Acesso em 15/06/2012.

ALVES Edgard (Org.). Modernização produtiva e relações de trabalho. Petrópolis, RJ: Vozes; Brasília, DF: IPEA, 1997.

ALVES, Shirlei Marly. A ética nas relações entre tutores e alunos em ambientes virtuais de aprendizagem: um olhar bakhtiniano sobre a identidade e a alteridade. Eutomia, ano IV, v. 1, p. 339-348, jul. 2011a.

ALVES, Shirlei Marly. A interação do trabalho docente do professor e do professor tutor:quem sou eu, quem és tu, quem somos nós? 2011. 52f. Monografia. (Especialização em Educação Continuada e a Distância) - Universidade de Brasília, Brasília, 2011b.

ANTUNES, Ricardo. Século XXI: a nova era da precarização estrutural do trabalho? In: DAL ROSSO, Sadi; FORTES, José Augusto Abreu Sá (Org.). Condições de trabalho no limiar do século XXI. Brasília: Épocca, 2008. p. 13-19.

ANTUNES, Ricardo. Os modos de ser da informalidade: rumo a uma nova era da precarização estrutural do trabalho? Serv. Soc. Soc., São Paulo, n. 107, p. 405-419, jul.-set. 2011.

BAKHTIN, Mikhail; VOLOCHINOV, Valentin. Marxismo e Filosofia da Linguagem: problemas fundamentais do método sociológico na ciência da linguagem. Tradução Michel Lahud e Yara Frateschi Vieira. 4. ed. São Paulo: Hucitec, 1988.

BAKHTIN, Mikhail. Estética da criação verbal. Tradução Maria Ermantina Galvão Gomes. 2.ed. São Paulo: Martins Fontes, 1997.

BAKHTIN, Mikhail. Para uma filosofia do ato responsável. Tradução Valdemir Miotello e Carlos Alberto Faraco. São Paulo: Pedro \& João Editores, 2010.

BELLONI, Maria Luísa. Professor coletivo: quem ensina a distância? In: Autores Associados, 2009.

BRAIT, Beth. A natureza dialógica da linguagem: formas e graus de representação dessa dimensão constitutiva. In: FARACO, Carlos Alberto; TEZZA, Cristóvão; CASTRO, Gilberto de. Diálogos com Bakhtin. Curitiba: Editora da UFPR, 1996.

BRASIL. Ministério da Educação. Fundo Nacional de Desenvolvimento da Educação. Resolução CD/FNDE $n^{\circ}$ 26, de 5 de junho de 2009. Disponível em: $<$ http://uab.capes.gov.br/images/ stories/downloads/legislacao/resolucao_fnde_n26.pdf $>$. 
CARVALHO, A. B. Os múltiplos papéis do professor em educação a distância: uma abordagem centrada na aprendizagem. In: ENCONTRO DE PESQUISA EDUCACIONAL DO NORTE E NORDESTE - EPENN, 18. Anais... Maceió, 2007.

CARVAlHO, A.B. Clínica do trabalho, clínica do real. Tradução Kátia Santorum e Suyanna Linhales Barker. Le journal dês psychologues, n. 185, mars 2001. Disponível em: $<$ http://www.pqv.unifesp.br/clotClindotrab-tradkslb.pdf $>$. Acesso em: 15 dez. 2011.

DEPOVER, Christian et al. Las plataformas de formación a distancia y la escena pedagógica: ¿Qué tipo de complementariedad? In: ALONSO, Cavadonga Lopez; BARRIO, Maria Matesanz del (Ed.). Las Plataformas de aprendizaje. Del mito a la realidade. Madrid: Biblioteca Nueva, 2009. p. 78-89.

DURRIVE, Louis. A atividade humana, simultaneamente intelectual e vital:esclarecimentos complementares de Pierre Pastré e Yves Schwartz. Trab. Educ. Saúde, Rio de Janeiro, v. 9, supl. 1, p. 47-67, 2011.

DURRIVE, Louis; SCHWARTZ, Yves. Glossário da ergologia. Laboreal, v. 4, n.1, p.23-28, 2008. p.25. Disponível em: <http://laboreal.up.pt/revista/artigo.php?id=48u56oTV 6582234396587;63882>. Acesso em: 12 abr. 2012.

FARACO, Carlos Alberto. Linguagem \& diálogo: as ideias linguísticas do Círculo de Bakhtin. São Paulo: Parábola Editorial, 2009.

FRANÇA, Maristela Botelho. Uma comunidade dialógica de pesquisa - atividade e movimentação discursiva nas situações de trabalho de recepcionistas de guichê hospitalar. 2002. Tese (Doutorado em Linguística Aplicada e Estudos da Linguagem) - Pontifícia Universidade Católica de São Paulo, São Paulo, 2002.

LACOSTE, Michèle. Fala, atividade, situação. In: DUARTE, Francisco; FEITOSA, Vera (Org.). Linguagem \& trabalho. Rio de Janeiro: Lucerna, 1998.

LOUSADA, Eliane Gouvêa; BARRICELLI, Ermelinda. Análise comparativa de textos que orientam o trabalho educacional: décadas diferentes, mesmas prescrições. Eutomia, ano IV, n. 8, p. 224-246, dez. 2011.

MATTAR, João. Tutoria e interação em educação a distância. São Paulo: Cengage Learning, 2012.

MILL, Daniel. Educação a distância e trabalho docente virtual: sobre tecnologia, espaços, tempos, coletividade e relações sociais de sexo na Idade Mídia. Belo Horizonte: FAE/UFMG. 2006. 322p. Tese (Doutorado em Educação) - Faculdade de Educação, Universidade Federal de Minas Gerais, 2006.
PONZIO, Augusto. A concepção bakhtiniana do ato como dar um passo. Tradução Valdemir Miotello \& Carlos Alberto Faraco. In: BAKHTIN, Mikhail M. Para uma filosofia do ato responsável. São Carlos: Pedro e João Editores, 2010. p. 9-38.

PORTO, Ludmila Mota de F. Pelo (re)conhecimento da ergolinguística. Eutomia, ano IV, n. 8, p. 269-291, dez. 2011.

PRETI, Oreste. O estado da arte sobre "tutoria": modelos e teorias em construção. Relatório de Pesquisa "O sistema de Orientação Acadêmica no curso de Pedagogia a distância da Universidade Federal de Mato Grosso. In: PRETI, Orestes; OLIVEIRA, Gleyva M.S. de. Projeto Les susthémes d'appui à l'étudiant dans Le domaine de la Formation à Distance: le tutorat. Programa CAERENAD - Téléuniversité du Québec, Canadá, ago. 2003. Disponível em: <http://www.uab.ufmt.br/ uab/images/artigos_site_uab/tutoria_estado_arte.pdf $>$. Acesso em: 23 set. 2011.

SAMPAIO, Maria Cristina Hennes. A ergologia e os estudos da linguagem e das práticas linguageiras em situações de trabalho. Artecomunicação, Recife, n. 8, p. 149-167, 2003.

SCHWARTZ, Yves. A abordagem do trabalho reconfigura nossa relação com os saberes acadêmicos: as antecipações do trabalho. Tradução de Ines Polegatto e Decio Rocha. In: SOUZA-ESILVA, Maria Cecília P.; FAÏTA, Daniel. Linguagem e trabalho: construção de objetos de análise no Brasil e na França. São Paulo: Cortez, 2002. p. 109-137.

SEMIÃO, Filomena Maria da Rosa Coelho. Tutoria: uma forma flexível de ensino e aprendizagem. 138 fl. 2009. Dissertação (Mestrado em Supervisão Pedagógica) - Departamento de Ciências da Educação, Universidade dos Açores, Ponta Delgada, 2009.

SILVEIRA, Regina Lúcia Barros Leal da. A importância do tutor no processo de aprendizagem a distância. Revista Iberoamericana de Educación, v. 36, n. 3, 25 jun. 2005.

SOUZA, Carlos Alberto de et al. Tutoria como espaço de interação em Educação a Distância. Revista Diálogo Educacional, Curitiba, v. 4, n. 13, p. 79-89, set.-dez. 2004.

TARDIF, Maurice; LESSARD, Claude. O trabalho docente. Elementos para uma teoria da docência como profissão de interações humanas. Tradução João Batista Kreuch. 6.ed. Petrópolis, RJ: Vozes, 2011.

Recebido: 15 de novembro de 2013

Aprovado: 10 de fevereiro de 2014

Contato: shirlei.alves42@hotmail.com 